\title{
Cold decade (AD 1810-1819) caused by Tambora (1815) and another (1809) stratospheric volcanic eruption
}

\author{
Jihong Cole-Dai, ${ }^{1}$ David Ferris, ${ }^{1}$ Alyson Lanciki, ${ }^{1}$ Joël Savarino, ${ }^{2}$ Mélanie Baroni, ${ }^{3}$ \\ and Mark H. Thiemens ${ }^{4}$ \\ Received 14 September 2009; revised 9 October 2009; accepted 16 October 2009; published 21 November 2009.
}

[1] Climate records indicate that the decade of $\mathrm{AD}$ 1810-1819 including "the year without a summer" (1816) is probably the coldest during the past 500 years or longer, and the cause of the climatic extreme has been attributed primarily to the 1815 cataclysmic Tambora eruption in Indonesia. But the cold temperatures in the early part of the decade and the timing of the Tambora eruption call into question the real climatic impact of volcanic eruptions. Here we present new evidence, based on sulfur isotope anomaly $\left(\Delta^{33} \mathrm{~S}\right)$, a unique indicator of volcanic sulfuric acid produced in the stratosphere and preserved in polar snow, and on the precise timing of the volcanic deposition in both polar regions, that another large eruption in 1809 of a volcano is also stratospheric and occurred in the tropics. The Tambora eruption and the undocumented 1809 eruption are together responsible for the unusually cold decade. Citation: Cole-Dai, J., D. Ferris, A. Lanciki, J. Savarino, M. Baroni, and M. H. Thiemens (2009), Cold decade (AD 1810-1819) caused by Tambora (1815) and another (1809) stratospheric volcanic eruption, Geophys. Res. Lett., 36, L22703, doi:10.1029/2009GL040882.

\section{Introduction}

[2] Major explosive volcanic eruptions emit into the atmosphere large amounts of ash and gases, often with immediate and destructive consequences for humans [Stothers, 1984]. Volcanic sulfur compounds (mainly $\mathrm{SO}_{2}$ ) are quickly oxidized to sulfuric acid forming sulfate aerosols that linger in the atmosphere for months to a few years. Large eruptions can impact climate [Robock, 2000], via radiative effects of the volcanic aerosols. Extraordinarily large eruptions injecting massive amounts of $\mathrm{SO}_{2}$ directly into the stratosphere can cause significant tropospheric and surface cooling [Robock, 2000]. Such eruptions in the tropics are capable of global impact, for their aerosols are distributed to both Northern and Southern Hemispheres. The global cooling effect of stratospheric volcanic aerosols provides the physical basis for the geoengineering proposition to counteract the human-enhanced greenhouse warming

\footnotetext{
${ }^{1}$ Department of Chemistry and Biochemistry, South Dakota State University, Brookings, South Dakota, USA.

${ }^{2}$ Laboratoire de Glaciologie et Géophysique de l'Environnement, Université Joseph Fourier-Grenoble 1, CNRS, Saint Martin d'Hères, France.

${ }^{3}$ CEREGE, UMR6635, Collège de France, Université Paul Cézanne, CNRS, Aix-en-Provence, France.

${ }^{4}$ Department of Chemistry and Biochemistry, University of California, San Diego, La Jolla, California, USA.
}

Copyright 2009 by the American Geophysical Union. 0094-8276/09/2009GL040882\$05.00 by injecting $\mathrm{SO}_{2}$ into the stratosphere [Crutzen, 2006; Wigley, 2006].

[3] Perhaps the best known historical example of the climatic impact of volcanic eruptions is "the year without a summer" (1816) following the great AD 1815 Tambora eruption [Stothers, 1984] on the Indonesian island of Sumbawa $\left(8.25^{\circ} \mathrm{S}, 118.00^{\circ} \mathrm{E}\right)$. In fact, the period of $1810-1819$ appears as the coldest decade over at least the past 500 years in many detailed climate records for the Northern Hemisphere and the tropics [Briffa et al., 1998; D'Arrigo et al., 2009; Jones et al., 1995]. The records show that not only were the post-Tambora years in the decade exceptionally cold, the pre-Tambora years, 1810 and 1811 in particular, also experienced significantly below-average temperatures. This raises a number of questions: How much of the cooling during this period was caused by Tambora and how much was due to other factors? Could the effect of aerosols on atmospheric energy budget be significantly overestimated [Myhre, 2009]? However, an important premise of these questions was that only one large, climate-impacting eruption (Tambora) occurred during the decade. If another large stratospheric eruption occurred shortly before 1815 , the combined impact of Tambora and the other eruption could have been responsible for the unusually cold decade. No eruption of the Tambora magnitude is found during the period of 1800-1814 in the records of volcanic eruptions that are based on eyewitness accounts [Simkin and Siebert, 1994], indirect observations of atmospheric effects [Lamb, 1970], and limited volcanological data [Newhall and Self, 1982]. However, these observation-based records are often incomplete, due to lack of systematic reporting and documentation prior to the twentieth century [Simkin and Siebert, 1994; Stothers and Rampino, 1983].

[4] Polar ice cores provide proxy records of explosive global volcanism over many millennia [Castellano et al., 2005; Cole-Dai et al., 2000; Hammer et al., 1997; Zielinski et al., 1994]. These records are based on the measurement of volcanic-derived sulfuric acid, pioneered by C.U. Hammer and colleagues [Hammer, 1977; Hammer et al., 1980], and have distinct advantages over the observation-based records such as global and continuous coverage of extended time periods [Gao et al., 2008]. Volcanic sulfate was found in the 1809-1811 snow layers of Greenland as well as Antarctica ice cores [e.g., Cole-Dai et al., 1997, 2000; Dai et al., 1991; Mosley-Thompson et al., 2003; Palmer et al., 2001], and was considered as evidence of a large eruption in the tropics that distributed volcanic aerosols to both hemispheres. However, evidence from tephra (fine volcanic ash) in ice cores [Kurbatov et al., 2006; Yalcin et al., 2006] suggests that the sulfuric acid deposits on the Greenland and Antarctica ice sheets may have resulted from small or moderate eruptions that 
occurred contemporaneously in the high latitudes of both hemispheres. Here we present more specific and compelling evidence than the bi-polar sulfuric acid deposition in 18101811 , in the form of unique isotopic composition of the volcanic sulfate in ice cores and of the precise timing of the volcanic deposition in the polar regions, to confirm a stratospheric eruption in 1809.

\section{Data and Methods}

\subsection{Ice Cores}

\subsubsection{Greenland}

[5] Four ice cores were drilled in 2007 in a small area (approximately $100 \mathrm{~m}^{2}$ ) at Summit $\left(72.5^{\circ} \mathrm{N}, 38.5^{\circ} \mathrm{W}\right.$ ), Greenland. Core length varied from 75 meters to 200 meters, encompassing approximately 250 to 900 years, respectively. One core was analyzed continuously for concentrations of major ionic chemical impurities (including $\mathrm{Na}^{+}, \mathrm{SO}_{4}^{2-}, \mathrm{Ca}^{2+}$ and $\mathrm{NO}_{3}^{-}$) with the technique of continuous flow analysis with ion chromatography, or CFA-IC [Cole-Dai et al., 2006].

\subsubsection{Antarctica}

[6] Several ice cores from Dome C and South Pole, Antarctica used in this work have been described previously [Baroni et al., 2008; Budner and Cole-Dai, 2003]. The 2000/2001 South Pole cores were discretely and continuously sampled and analyzed with ion chromatography [Budner and Cole-Dai, 2003]. New for this work are two ice cores from WAIS Divide $\left(79.5^{\circ} \mathrm{S}, 112.0^{\circ} \mathrm{W}\right)$, West Antarctica, obtained as part of the West Antarctica Ice Sheet (WAIS) Divide Ice Core Project. The 130-m WDC05Q core was drilled in 2005/2006, and the 2006/2007 WDC06A core is the top $114 \mathrm{~m}$ of the anticipated WAIS Divide deep core $(\sim 3500 \mathrm{~m})$. Both were analyzed continuously with CFA-IC for major ionic chemicals.

[7] All ice cores are dated with high accuracy and precision using the technique of counting annual cycles of ionic concentrations. Details of the dating procedures are included in the auxiliary material. ${ }^{1}$

\subsection{Volcanic Sulfate and Isotope Analysis}

[8] Prominent volcanic events including Tambora and the 1809 eruptions were identified in ice cores by the elevated sulfate concentrations and the years when the elevated concentrations appear [e.g., Cole-Dai et al., 1997]. Depth intervals of the ice cores containing the sulfate of a volcanic event or of the non-volcanic background were decontaminated and melted, and the sulfate was extracted from the meltwater and purified as sulfuric acid using procedures described previously [Savarino et al., 2003a; Baroni et al., 2008]. The sulfuric acid was subsequently converted, through a series of chemical reactions, to $\mathrm{SF}_{6}$ gas, which was analyzed for sulfur isotope composition using isotope ratio mass spectrometry and established procedures [Rai and Thiemens, 2007; Savarino et al., 2001].

\section{Results and Discussion}

[9] Ice core records have uncovered past eruptions that left no eyewitness reports or contemporary observational

\footnotetext{
${ }^{1}$ Auxiliary materials are available in the HTML. doi:10.1029/ 2009 GL040882.
}

documentation and therefore do not appear in the observation-based records. The missing may be major eruptions that have certainly impacted climate. For example, the AD 1452 or 1453 stratospheric eruption of the Kuwae volcano in the equatorial Pacific $\left(16.8^{\circ} \mathrm{S}, 168.5^{\circ} \mathrm{E}\right)$, one of the most explosive eruptions in the last millennium in terms of atmospheric aerosol mass loading, has been found only in polar ice cores [Gao et al., 2006]. With regard to the early nineteenth century, an initial study [Dai et al., 1991] found high concentrations of sulfuric acid in the 1810-1811 snow layers in a few ice cores from Greenland and Antarctica and suggested that a stratospheric eruption occurred around the year of 1809 , six years before the Tambora eruption. The volcanic fallout in both polar regions indicated the volcano was in the tropics, for only large eruptions in the tropics can deposit volcanic sulfuric acid in both polar regions. Results of subsequent studies [Cole-Dai et al., 1997, 2000; Mosley-Thompson et al., 2003; Palmer et al., 2001] confirm the presence of volcanic sulfuric acid in the 1810-1811 snow layers across Greenland and Antarctica.

[10] However, small or moderate eruptions emitting only tropospheric $\mathrm{SO}_{2}$ occur frequently, with no significant largescale climatic impact [Robock, 2000; Simkin and Siebert, 1994]. Tropospheric eruptions in the high and mid-latitudes of Northern or Southern Hemisphere can also deposit volcanic sulfuric acid on the polar ice sheet of the respective hemisphere. Consequently, simultaneous sulfuric acid signals in bi-polar ice core records may be from coincidental tropospheric eruptions of volcanoes in the high/mid-latitudes of both hemispheres, and such signals alone are insufficient to confirm a past stratospheric eruption by a volcano in the tropics. A recent study [Yalcin et al., 2006] found tephra in the 1809 snow layer in an Arctic (Yukon Territory, Canada) ice core with chemical composition suggesting that a small or moderate volcanic eruption occurred that year in the high northern latitudes. The chemical composition of tephra in the 1809-1810 layer of a Siple Dome, West Antarctica ice core is reported [Kurbatov et al., 2006] to be consistent with that of ash from Antarctic volcanoes. These reports suggest that two contemporaneous but separate small or moderate eruptions, one in the high latitudes of the Northern Hemisphere and another in Antarctica, could be the sources of the volcanic sulfuric acid found in Greenland and Antarctica ice cores, respectively. This suggestion implies no large-scale climatic impact by volcanic eruption in the years immediately preceding the 1815 Tambora eruption, for only stratospheric eruptions in the tropics can cause significant global cooling [Robock, 2000].

[11] Volcanic emissions also impact atmospheric composition and chemistry. Sulfur dioxide in the stratosphere undergoes oxidation to $\mathrm{H}_{2} \mathrm{SO}_{4}$ with reaction pathways different from those in the troposphere [Baroni et al., 2007, 2008; Savarino et al., 2003a, 2003b]. A unique indicator of the stratospheric $\mathrm{SO}_{2}-\mathrm{to}-\mathrm{H}_{2} \mathrm{SO}_{4}$ conversion process appears to be the ${ }^{33} \mathrm{~S}$ isotope anomaly, $\Delta^{33} \mathrm{~S}$ (see Text S1 of the auxiliary material), created via mass independent fractionation (MIF) during the $\mathrm{SO}_{2}$ photochemical reaction process and retained in the oxidation end product $\left(\mathrm{H}_{2} \mathrm{SO}_{4}\right)$ and eventually preserved in polar snow [Baroni et al., 2007; Savarino et al., 2003b]. Laboratory studies 
Table 1. Sulfur-33 MIF values and uncertainty (\%) of volcanic sulfate from the Tambora, the 1809 and Kuwae Eruptions ${ }^{\mathrm{a}}$

\begin{tabular}{|c|c|c|c|c|c|c|c|}
\hline \multirow[b]{2}{*}{ Ice Core Location } & \multirow[b]{2}{*}{ Sample Type } & \multicolumn{2}{|c|}{ Tambora } & \multicolumn{2}{|c|}{1809 Eruption } & \multicolumn{2}{|c|}{ Kuwae } \\
\hline & & $\Delta^{33} \mathrm{~S}, \%$ & Uncertainty & $\Delta^{33} \mathrm{~S}, \%$ & Uncertainty & $\Delta^{33} \mathrm{~S}, \%$ & Uncertainty \\
\hline \multicolumn{8}{|l|}{ Antarctica } \\
\hline Dome $\mathrm{C}$ & Single sample & No data & & +0.10 & \pm 0.17 & $-0.06^{\mathrm{b}}$ & $\pm 0.12^{\mathrm{b}}$ \\
\hline South Pole & Single sample & $+0.15^{\mathrm{b}}$ & $\pm 0.12^{\mathrm{b}}$ & -0.003 & \pm 0.12 & $+0.25^{\mathrm{b}}$ & $\pm 0.10^{\mathrm{b}}$ \\
\hline South Pole & Early & +0.20 & \pm 0.12 & No data & & +0.60 & \pm 0.12 \\
\hline South Pole & Late & -0.60 & \pm 0.12 & No data & & -0.55 & \pm 0.26 \\
\hline \multicolumn{8}{|l|}{ Greenland } \\
\hline Summit & Early & +0.23 & \pm 0.08 & +0.18 & \pm 0.08 & No data & \\
\hline Summit & Late & -0.28 & \pm 0.08 & -0.12 & \pm 0.08 & No data & \\
\hline
\end{tabular}

a"Early" or "Late" refers to the time period during a volcanic eruption represented by the sample.

"Presented previously [Baroni et al., 2008].

[Farquhar et al., 2001] demonstrate that the MIF isotope anomaly is generated by UV (wavelength $<310 \mathrm{~nm}$ ) photolysis of $\mathrm{SO}_{2}$. Shielding of the solar UV-B and UV-C radiation by stratospheric ozone prevents similar photolysis in the troposphere. Therefore $\mathrm{H}_{2} \mathrm{SO}_{4}$ from the oxidation of tropospheric $\mathrm{SO}_{2}$ carries no MIF anomaly, and only stratospheric eruptions may result in $\triangle^{33} \mathrm{~S}$ anomaly in the $\mathrm{H}_{2} \mathrm{SO}_{4}$. The MIF anomaly provides a technique to distinguish climatically important stratospheric eruptions from tropospheric eruptions in polar ice cores. Volcanic sulfate of known stratospheric eruptions in the last 1000 years in Antarctica ice cores is characterized by significant non-zero $\Delta^{33}$ S values [Baroni et al., 2007, 2008; Savarino et al., $2003 \mathrm{~b}$ ], while zero $\Delta^{33} \mathrm{~S}$ (within the analytical uncertainty) was observed in all tropospherically produced sulfate (both volcanic and non-volcanic).

[12] Initially, the volcanic sulfate from the 1810-1811 snow layers of a few Antarctica ice cores was measured for MIF anomaly. The $\Delta^{33} \mathrm{~S}$ of the volcanic sulfate in samples from Dome $\mathrm{C}$ and South Pole cores $(+0.10 \%$ and $-0.003 \%$, respectively, Table 1) was within the respective analytical uncertainties $( \pm 0.17 \%$ and $\pm 0.12 \%$ ) of the instrumental technique, and therefore showed no anomaly. However, zero $\Delta^{33} \mathrm{~S}$ value of a single volcanic sample does not necessarily indicate a non-stratospheric eruption. Baroni et al. [2007] discovered that the $\Delta^{33} \mathrm{~S}$ value of a volcanic event in Antarctic snow changes with time from positive to negative during the $\mathrm{SO}_{2}-$ to- $\mathrm{H}_{2} \mathrm{SO}_{4}$ conversion. A net zero $\Delta^{33} \mathrm{~S}$ in all of the oxidation product of an eruption is required by ${ }^{33} \mathrm{~S}$ mass balance; thus if all $\mathrm{H}_{2} \mathrm{SO}_{4}$ of a stratospheric eruption is preserved in polar ice and collected in a single sample, or when a sample contains equal amount of $\mathrm{H}_{2} \mathrm{SO}_{4}$ with positive and negative $\Delta^{33} \mathrm{~S}$, the $\Delta^{33} \mathrm{~S}$ will be zero [Baroni et al., 2007, 2008]. This is illustrated by the absence of MIF anomaly $\left(\Delta^{33} \mathrm{~S}=\right.$ $-0.06 \%$, uncertainty $\pm 0.12 \%$, Table 1 ) of the Kuwae sulfate in the Dome $\mathrm{C}$ core, compared with non-zero $\Delta^{33} \mathrm{~S}(+0.25 \%)$ of a Kuwae sample in a South Pole core. The former probably contained equal amounts of sulfate with positive and negative $\Delta^{33} \mathrm{~S}$, while the latter contained more sulfate with positive $\Delta^{33} \mathrm{~S}$. Therefore, $\Delta^{33} \mathrm{~S}$ measurement on at least two time-resolved samples of an eruption is necessary to ascertain that the eruption is stratospheric [Baroni et al., 2007]. Owing to limited amounts of ice containing volcanic sulfate in the Antarctica cores, only one sulfate sample from the 1810-1811 snow layers at each location was obtained for $\Delta^{33} \mathrm{~S}$ measurement and no $\Delta^{33} \mathrm{~S}$ anomaly was found in these single samples of the event (Table 1).

[13] The 2007 Summit, Greenland ice cores provided the first Northern Hemisphere volcanic sulfate samples for sulfur MIF anomaly measurement. Two samples (early and late deposition) of the volcanic sulfate were obtained from the $1810-1811$ layers of the four cores. The $\Delta^{33} \mathrm{~S}$ of the early volcanic sulfate is $+0.18 \%$ and that of the late volcanic sulfate is $-0.12 \%$, both significantly different from zero (uncertainty $\pm 0.08 \%$ ). The two time-resolved samples of the Tambora eruption in the same cores also show positive (early) and negative (late) $\Delta^{33} \mathrm{~S}$ values (Table 1).

[14] The $\Delta^{33} \mathrm{~S}$ anomaly of volcanic sulfate in the 1810 1811 snow layers in Greenland and the same positive-tonegative $\Delta^{33} \mathrm{~S}$ change for the Tambora sulfate and the earlier volcanic sulfate provide new and independent evidence that a stratospheric eruption occurred during or around the year of 1809 . Because $\Delta^{33} \mathrm{~S}$ anomaly has not been found in the 1810-1811 volcanic sulfate in Antarctica (no time-resolved sulfate samples have been obtained), the Greenland $\Delta^{33} \mathrm{~S}$ anomaly does not directly lead to the conclusion that the 1809 stratospheric eruption occurred in the tropics and is responsible for the volcanic deposition in both polar regions. To determine whether the volcanic deposition in the 1810-1811 layers in Greenland and Antarctica came from a single eruption, we examined the precise timing of the deposition in each polar region using the sub-annually dated Antarctica and Greenland ice cores. The deposition from the Tambora eruption and from the 1809 eruption(s) can be seen in two pairs of West Antarctica and South Pole cores (Figures 1a and 1b) and in three Summit, Greenland cores (Figure 1c). From the mid-point of the Tambora deposition period to the mid-point of the deposition of the 1809 volcanic sulfate, the average lengths of time are 77 (range 75-81, Table S1 of the auxiliary material) months in Antarctica and 72 (range 71-73) months in Greenland (Table 2 and Figure 1). The overlap between these times is significant, given the uncertainty ( \pm 4 months) of the sub-annual dating (see Text S1 of the auxiliary material), and indicates that the deposition of the 1809 volcanic sulfate occurred essentially at the same time in Antarctica and in Greenland. In addition, the deposition of the 1809 volcanic sulfate lasted approximately 19 months (average deposition time in Antarctica and Greenland), very similar to that (20 months) for Tambora. Furthermore, the ratios of the deposition flux of the 1809 volcanic sulfate to 


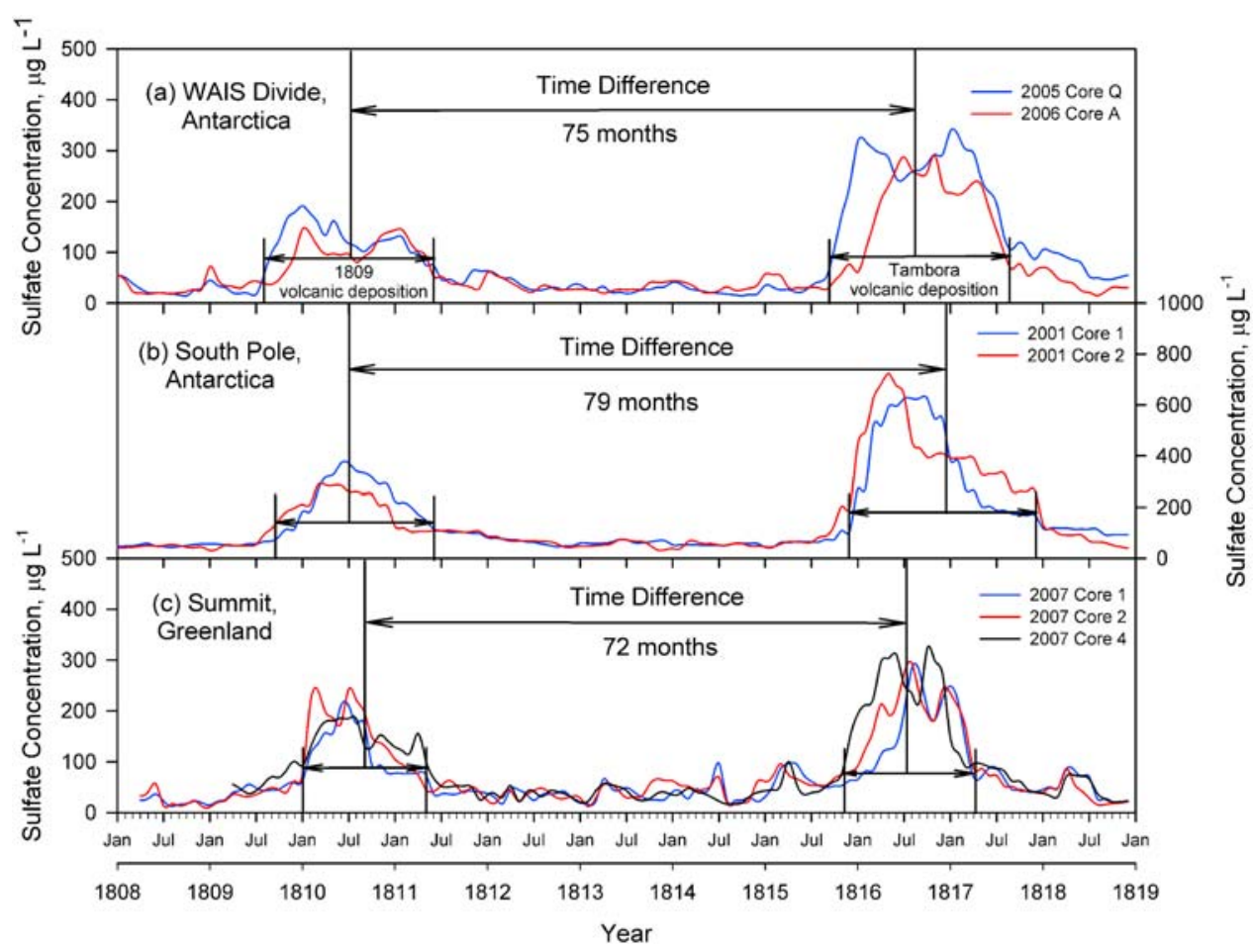

Figure 1. Sulfate deposition from the Tambora and 1809 volcanic eruptions in Antarctica and Greenland ice cores. The length of a deposition period is determined by the continuous elevation of sulfate concentration above the non-volcanic background. Time difference is the length of time between the mid-point of Tambora deposition and that of the 1809 eruption.

Table 2. Timing and Volcanic Flux of the April, 1815 Tambora Eruption and the 1809 Eruption in Antarctica and Greenland Ice Core ${ }^{\mathrm{a}}$

\begin{tabular}{|c|c|c|c|c|c|c|c|c|}
\hline \multirow[b]{2}{*}{ Ice Core } & \multicolumn{3}{|c|}{ Tambora } & \multicolumn{3}{|c|}{1809 Eruption } & \multirow[b]{2}{*}{$\begin{array}{c}\text { Time } \\
\text { Difference } \\
\text { (months) }\end{array}$} & \multirow[b]{2}{*}{$\begin{array}{c}\text { Ratio } \\
\left(f \mid f_{\text {Tambora }}\right)\end{array}$} \\
\hline & $\begin{array}{c}\text { Length } \\
\text { (months) }\end{array}$ & $\begin{array}{l}\text { Mid-point } \\
\text { (month) }\end{array}$ & $\begin{array}{c}\text { Volcanic } \\
\text { Flux } f \\
\left(\mathrm{~kg} \mathrm{~km}^{-2}\right)\end{array}$ & $\begin{array}{c}\text { Length } \\
\text { (months) }\end{array}$ & $\begin{array}{c}\text { Mid-point } \\
\text { (month) }\end{array}$ & $\begin{array}{c}\text { Volcanic } \\
\text { Flux } f \\
\left(\mathrm{~kg} \mathrm{~km}^{-2}\right)\end{array}$ & & \\
\hline \multicolumn{9}{|l|}{ Antarctica } \\
\hline $\mathrm{SP} 01^{\mathrm{b}}$ & 25 & Jan 1817 & 66 & 21 & Jun 1810 & 29 & 79 & 0.44 \\
\hline $\mathrm{WDC}^{\mathrm{c}}$ & 22 & Oct 1816 & 81 & 22 & Jul 1810 & 41 & 75 & 0.51 \\
\hline $\operatorname{SI} 85^{\mathrm{d}}$ & & & 129 & & & 53 & & 0.41 \\
\hline DY $89^{\mathrm{d}}$ & & & 90 & & & 54 & & 0.60 \\
\hline Law Dome ${ }^{e}$ & & & 80 & & & 45 & & 0.56 \\
\hline Plateau Remote $\mathrm{f}$ & & & 22 & & & 8.3 & & 0.37 \\
\hline Dome $\mathrm{C}^{\mathrm{g}}$ & & & 39 & & & 10.2 & & 0.26 \\
\hline Average & 23 & & & 21 & & & 77 & 0.45 \\
\hline \multicolumn{9}{|l|}{ Greenland } \\
\hline SU0 ${ }^{7}$ & 17 & Sep 1816 & 59 & 17 & Sep 1810 & 36 & 72 & 0.60 \\
\hline ST89 & & & 47 & & & 28 & & 0.60 \\
\hline GITS $^{\mathrm{i}}$ & & & 48 & & & 33 & & 0.69 \\
\hline$D 3^{i}$ & & & 85 & & & 47 & & 0.55 \\
\hline Average & & & & & & & 72 & 0.61 \\
\hline
\end{tabular}

${ }^{\mathrm{a}}$ Time difference refers to the number of months between the mid-point of Tambora deposition and that of the 1809 eruption deposition.

${ }^{\mathrm{b}}$ Budner and Cole-Dai [2003].

${ }^{\mathrm{c}}$ This work.

${ }^{\mathrm{d}}$ Cole-Dai et al. [1997].

${ }^{\mathrm{e}}$ Palmer et al. [2001].

${ }^{\mathrm{f} C o l e-D a i}$ et al. [2000].

${ }^{\mathrm{g}}$ Castellano et al. [2005].

${ }^{\mathrm{h}}$ Dai et al. [1991].

${ }^{\mathrm{i}}$ Mosley-Thompson et al. [2003]. 
that of the Tambora eruption are very similar at the two polar regions: the mean ratio is 0.45 (range $0.26-0.60$ ) in Antarctica, compared to 0.61 (range $0.55-0.69$ ) in Greenland (Table 2).

\section{Conclusions}

[15] The $\Delta^{33} \mathrm{~S}$ anomaly of the 1809 volcanic sulfate in Greenland and the similar deposition characteristics (timing and flux) of the volcanic sulfate on opposite polar ice sheets lead us to conclude that a large stratospheric eruption occurred in 1809 and the volcano is located in the tropics. This conclusion does not preclude the possibility that contemporaneous, small or moderate eruptions occurred in the high/mid-latitudes of both hemispheres at approximately the same time; these eruptions may have left the tephra found in the Yukon (the Arctic) and Siple Dome (Antarctica) ice cores, but would have had no significant impact on the magnitude of the volcanic signals in the ice cores or on the global climate. It may also be possible that the tephra is part of the background dust particles in the atmosphere, not necessarily from contemporaneous volcanic eruptions.

[16] The probable date or month of the 1809 eruption can be determined from the ice core timing data. Tambora erupted in April, 1815 [Stothers, 1984]. The sub-annually dated ice core records show that the deposition of Tambora sulfate lasted 16-25 months (Table 2). The deposition midpoint falls in the second half (July-December) of 1816 in both polar regions, suggesting that the time for transport and deposition of volcanic aerosols at the poles from a lowlatitude stratospheric eruption is approximately 18 months (from April, 1815 to October, 1816). The deposition midpoint of the 1809 eruption is in the July-September period of 1810 (Figure 1 and Table 2). Applying the 18-month transport and deposition time from the Tambora data results in a likely date of February, 1809 for the 1809 eruption. This date is tentative, owing to the uncertainties of the ice core-derived months and the actual difference between Northern and Southern Hemisphere in atmospheric meridional transport of tropical stratospheric aerosols influenced by the season and the quasi-biennial oscillation in stratospheric circulation [Trepte and Hitchman, 1992]. Nonetheless, it is possible to conclude that the eruption occurred near the beginning of 1809 . This is consistent with temperature records reconstructed from tree rings and corals [Briffa et al., 1998; D'Arrigo et al., 2009] showing that the years of 1809,1810 and 1811 were much colder than the long term temperature average.

[17] Acknowledgments. We thank Ice Coring and Drilling Services, University of Wisconsin for field assistance in the drilling of the ice cores. T. Jackson contributed to the sulfur isotope analysis. Financial support provided by NSF Office of Polar Programs via awards 0087151, 0337933, 0538553 and 0612461 to J.C-D.; 0338363 and 0612422 to M.H.T. J.S. acknowledges the French Polar Institute (IPEV) and the Institut National des Sciences de l'Univers (INSU) for financial supports through their Arctic and LEFE programs.

\section{References}

Baroni, M., M. H. Thiemens, R. J. Delmas, and J. Savarino (2007), Massindependent sulfur isotopic compositions in stratospheric volcanic eruptions, Science, 315, 84-87, doi:10.1126/science.1131754.

Baroni, M., J. Savarino, J. Cole-Dai, V. K. Rai, and M. H. Thiemens (2008), Anomalous sulfur isotope composition of volcanic sulfate over the last millennium in Antarctic ice cores, J. Geophys. Res., 113, D20112, doi:10.1029/2008JD010185.

Briffa, K. R., P. D. Jones, F. H. Schweingruber, and T. J. Osborn (1998), Influence of volcanic eruptions on Northern Hemisphere summer temperature over the past 600 years, Nature, 393, 450-455, doi:10.1038/ 30943.

Budner, D., and J. Cole-Dai (2003), The number and magnitude of large explosive volcanic eruptions between 904 and 1865 A.D.: Quantitative evidence from a new South Pole ice core, in Volcanism and the Earth's Atmosphere, vol. 139, edited by A. Robock and C. Oppenheimer, pp. 165-176, AGU, Washington, D. C.

Castellano, E., S. Becagli, M. Hansson, M. Hutteli, J. R. Petit, M. R. Rampino, M. Severi, J. P. Steffensen, R. Traversi, and R. Udisti (2005), Holocene volcanic history as recorded in the sulfate stratigraphy of the European Project for Ice Coring in Antarctica Dome C (EDC96) ice core, J. Geophys. Res., 110, D06114, doi:10.1029/2004JD005259.

Cole-Dai, J., E. Mosley-Thompson, and L. G. Thompson (1997), Annually resolved southern hemisphere volcanic history from two Antarctic ice cores, J. Geophys. Res., 102, 16,761-16,771, doi:10.1029/97JD01394.

Cole-Dai, J., E. Mosley-Thompson, S. P. Wight, and L. G. Thompson (2000), A 4100-year record of explosive volcanism from an East Antarctica ice core, J. Geophys. Res., 105, 24,431-24,441, doi:10.1029/ 2000JD900254.

Cole-Dai, J., D. M. Budner, and D. G. Ferris (2006), High speed, high resolution, and continuous chemical analysis of ice cores using a melter and ion chromatography, Environ. Sci. Technol., 40, 6764-6769, doi:10.1021/es061188a.

Crutzen, P. J. (2006), Albedo enhancement by stratospheric sulfur injections: A contribution to resolve a policy dilemma?, Clim. Change, 77, 211-220, doi:10.1007/s10584-006-9101-y.

D’Arrigo, R., R. Wilson, and A. Tudhope (2009), The impact of volcanic forcing on tropical temperatures during the past four centuries, Nat. Geosci., 2, 51-55, doi:10.1038/ngeo393.

Dai, J., E. Mosley-Thompson, and L. G. Thompson (1991), Ice core evidence for an explosive tropical volcanic eruption 6 years preceding Tambora, J. Geophys. Res., 96(D9), 17,361-17,366, doi:10.1029/91JD01634.

Farquhar, J., J. Savarino, S. Airieau, and M.H. Thiemens (2001), Observation of wavelength-sensitive mass-independent sulfur isotope effects during $\mathrm{SO}_{2}$ photolysis: Implications for the early atmosphere, J. Geophys. Res., 106, 32,829-32,832, 841, doi:10.1029/2000JE001437.

Gao, C., A. Robock, S. Self, J. B. Witter, J. P. Steffensen, H. B. Clausen, M.-L. Siggaard-Anderson, S. Johnsen, P. A. Mayewski, and C. M. Ammann (2006), The 1452 or 1453 A.D. Kuwae eruption signal derived from multiple ice core records: Greatest volcanic sulfate event of the last 700 years, J. Geophys. Res., 111, D12107, doi:10.1029/2005JD006710.

Gao, C., A. Robock, and C. Ammann (2008), Volcanic forcing of climate over the past 1500 years: An improved ice core-based index for climate models, J. Geophys. Res., 113, D23111, doi:10.1029/2008JD010239.

Hammer, C. U. (1977), Past volcanism revealed by Greenland ice sheet impurities, Nature, 270, 482-486, doi:10.1038/270482a0.

Hammer, C. U., H. B. Clausen, and W. Dansgaard (1980), Greenland ice sheet evidence of post-glacial volcanism and its climatic impact, Nature, 288, 230-235, doi:10.1038/288230a0.

Hammer, C. U., H. B. Clausen, and C. C. Jr. Langway (1997), 50,000 years of recorded global volcanism, Clim. Change, 35, 1-15, doi:10.1023/ A:1005344225434

Jones, P. D., K. R. Briffa, and F. H. Schweingruber (1995), Tree-ring evidence of the widespread effects of explosive volcanic eruptions, Geophys. Res. Lett., 22, 1333-1336, doi:10.1029/94GL03113.

Kurbatov, A. V., G. A. Zielinski, N. W. Dunbar, P. A. Mayewski, E. A. Meyerson, S. B. Sneed, and K. C. Taylor (2006), A 12,000 year record of explosive volcanism in the Siple Dome Ice Core, West Antarctica, J. Geophys. Res., 111, D12307, doi:10.1029/2005JD006072.

Lamb, H. H. (1970), Volcanic dust in the atmosphere, with a chronology and assessment of its meteorological significance, Philos. Trans. R. Soc. London, Ser. A, 266, 425-533, doi:10.1098/rsta.1970.0010.

Mosley-Thompson, E., T. A. Mashiotta, and L. G. Thompson (2003), Highresolution ice core records of Late Holocene volcanism: Current and future contributions from the Greenland PARCA cores, in Volcanism and the Earth's Atmosphere, Geophys. Monogr. Ser., vol. 139, edited by A. Robock and C. Oppenheimer, pp. 153-164, AGU, Washington, D. C. Myhre, G. (2009), Consistency between satellite-derived and modeled estimates of the direct aerosol effect, Science, 325, 187-190, doi:10.1126/ science. 1174461 .

Newhall, C. G., and S. Self (1982), The Volcanic Explosivity Index (VEI): An estimate of explosive magnitude for historical volcanism, J. Geophys. Res., 87, 1231-1238, doi:10.1029/JC087iC02p01231.

Palmer, A. S., T. D. van Ommen, M. A. J. Curran, V. Morgan, J. M. Souney, and P. A. Mayewski (2001), High-precision dating of volcanic events (A.D. 1301-1995) using ice cores from Law Dome, Antarctica, J. Geophys. Res., 106, 28,089-28,095, doi:10.1029/2001JD000330. 
Rai, V. K., and M. H. Thiemens (2007), Mass independently fractionated sulfur components in chondrites, Geochim. Cosmochim. Acta, 71, $1341-$ 1354, doi:10.1016/j.gca.2006.11.033.

Robock, A. (2000), Volcanic eruptions and climate, Rev. Geophys., 38, 191-219, doi:10.1029/1998RG000054.

Savarino, J., B. Alexander, V. Darmohusodo, and M. H. Thiemens (2001), Sulfur and oxygen isotope analysis of sulfate at micromole levels using a pyrolysis technique in a continuous flow system, Anal. Chem., 73, 44574462, doi:10.1021/ac010017f.

Savarino, J., S. Bekki, J. Cole-Dai, and M. H. Thiemens (2003a), Evidence of sulfate mass independent oxygen isotopic compositions of dramatic changes in atmospheric oxidation following massive volcanic eruptions, J. Geophys. Res., 108(D21), 4671, doi:10.1029/2003JD003737.

Savarino, J., A. Romero, J. Cole-Dai, S. Bekki, and M. H. Thiemens (2003b), UV induced mass-independent sulfur isotope fractionation in stratospheric volcanic sulfate, Geophys. Res. Lett., 30(21), 2131 doi:10.1029/2003GL018134.

Simkin, T., and L. Siebert (1994), Volcanoes of the World, 2nd ed., Geoscience, Tucson, Ariz.

Stothers, R. B. (1984), The great Tambora eruption in 1815 and its aftermath, Science, 224, 1191-1197, doi:10.1126/science.224.4654.1191.

Stothers, R. B., and M. R. Rampino (1983), Historic volcanism, European dry fogs, and Greenland acid precipitation, 1500 B.C. to A.D. 1500 , Science, 222, 411-413, doi:10.1126/science.222.4622.411.

Trepte, C. R., and M. H. Hitchman (1992), The stratospheric tropical circulation deduced from aerosol satellite data, Nature, 355, 626-628, doi:10.1038/355626a0.
Wigley, T. M. L. (2006), A combined mitigation/geoengineering approach to climate stabilization, Science, 314, 452-454, doi:10.1126/ science. 1131728 .

Yalcin, K., C. P. Wake, K. J. Kreutz, M. S. Germani, and S. I. Whitlow (2006), Ice core evidence for a second volcanic eruption around 1809 in the Northern Hemisphere, Geophys. Res. Lett., 33, L14706, doi:10.1029/ 2006GL026013.

Zielinski, G. A., P. A. Mayewski, L. D. Meeker, S. Whitlow, M. S. Twickler, M. Morrison, D. A. Meese, A. J. Gow, and R. B. Alley (1994), Record of volcanism since 7000 B.C. form the GISP2 Greenland ice core and implications for the volcano-climate system, Science, 264, 948-952, doi:10.1126/science.264.5161.948.

M. Baroni, CEREGE, UMR6635, Collège de France, Université Paul Cézanne, CNRS, Europôle Méditerranéen de l'Arbois, BP 80, F-13545 Aix-en-Provence CEDEX, France.

J. Cole-Dai, D. Ferris, and A. Lanciki, Department of Chemistry and Biochemistry, South Dakota State University, Brookings, SD 57007, USA. (jihong.cole-dai@sdstate.edu)

J. Savarino, Laboratoire de Glaciologie et Géophysique de l'Environnement, Université Joseph Fourier-Grenoble 1, CNRS, F-38400 Saint Martin d'Hères CEDEX, France.

M. H. Thiemens, Department of Chemistry and Biochemistry, University of California, San Diego, La Jolla, CA 92193, USA 